\title{
Cooldown Numbers
}

\author{
F. M. Jaruszewski
}

\section{$5 / 1 / 85$}

Revised $8 / 14 / 87$ S. J. Wintercorn

D-Zero Engineering Note 3740.000-EN-106 
Report on cooldown refrigeration of D-Zero cryostats

$\begin{array}{ll}* * * * * * * * * * * * * * * * * * * * * * * * * * * * * * * * * * * * * * * * * * * * * * * * * * * * * * * * * * * \\ * & \text { Density of materials in cryostat } \\ * & * \\ * & \text { Copper }-8.96 \mathrm{~g} / \mathrm{cc} \\ * & 6-10-1.7 \mathrm{~g} / \mathrm{cc} \\ * & \text { Uranium }-19.0 \mathrm{~g} / \mathrm{cc} \\ * & \text { Stainless Steel }(304)-8.03 \mathrm{~g} / \mathrm{cc}\end{array}$

$\begin{array}{ll}* * * * * * * * * * * * * * * * * * * * * * * * * * * * * * * * * * * * * * * * * * * * * * * * * * * * * * * * * * \\ * & \text { Enthalpy change of materials }(300 \mathrm{~K}-90 \mathrm{~K}) \\ * & * \\ * & \text { Copper }-73.75 \mathrm{~J} / \mathrm{g} \\ * & 6-10-110 \mathrm{~J} / \mathrm{g} \\ * & \text { Uranium }-22.15 \mathrm{~J} / \mathrm{g} \\ * & \text { Stainless Steel }(304)-70 \mathrm{~J} / \mathrm{g} \\ * * * * * * * * * * * * * * * * * * * * * * * * * * * * * * * * * * * * * * * * * * * * * * * * * * * *\end{array}$

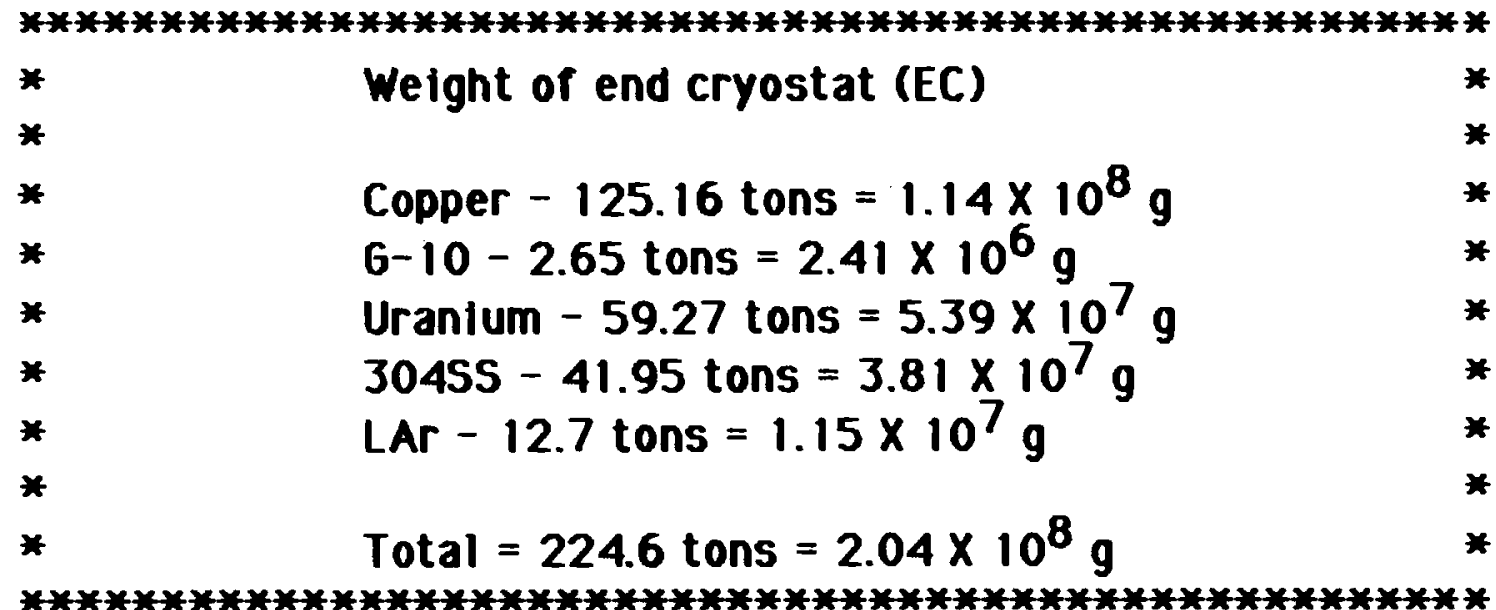

$\begin{array}{ll}* * * * * * * * * * * * * * * * * * * * * * * * * * * * * * * * * * * * * * * * * * * * * * * * * * * * \\ * & \text { Weight of center cryostat } \\ * & \text { Copper }-117.14 \text { tons }=1.06 \times 10^{8} \mathrm{~g} \\ * & \text { G-10-5.07 tons }=4.61 \times 10^{6} \mathrm{~g} \\ * & \text { Uranium - } 156.9 \text { tons }=1.43 \times 10^{8} \mathrm{~g} \\ * & \text { 3045S - 31.5 tons }=2.86 \times 10^{7} \mathrm{~g} \\ * & \text { LAr }-30.33 \text { tons }=2.76 \times 10^{7} \mathrm{~g} \\ * & \end{array}$




$\begin{array}{ll}* * * * * * * * * * * * * * * * * * * * * * * * * * * * * * * * * * * * * * * * * * * * * * * * * * * * * * * * \\ * & \text { Cooldown loads of an end cryostat } \\ * & \text { Copper }-8.41 \times 10^{9} \mathrm{~J} \\ * & 6-10-2.65 \times 10^{8} \mathrm{~J} \\ * & \text { Uranium }-1.20 \times 10^{9} \mathrm{~J} \\ * & 3045 S-2.67 \times 10^{9} \mathrm{~J} \\ * & \\ * & \text { Total }=1.25 \times 10^{*} \mathrm{~J}\end{array}$

$\begin{array}{ll}* * * * * * * * * * * * * * * * * * * * * * * * * * * * * * * * * * * * * * * * * * * * * * * * * * * * \\ * & \text { Cooldown loads of central cryostat } \\ * & \text { Copper }-7.82 \times 10^{9} \mathrm{~J} \\ * & 6-10-5.07 \times 10^{8} \mathrm{~J} \\ * & \text { Uranium }-3.17 \times 10^{9} \mathrm{~J} \\ * & 30455-2.00 \times 10^{9} \mathrm{~J} \\ * & \end{array}$

$\begin{array}{ll}* * * * * * * * * * * * * * * * * * * * * * * * * * * * * * * * * * * * * * * * * * * * * * * * * * * * * \\ * & \text { Total load of an end cryostat } \\ * & 1.25 \times 10^{10} \mathrm{~J}+5 \mathrm{Kw}(\mathrm{est}) \\ * & \text { Max. refrigeration avallable: } 45 \mathrm{Kw} \text { ( } 88 \mathrm{~K} \\ * & \text { Min. time to cooldown: } 73.1 \mathrm{hours}\end{array}$

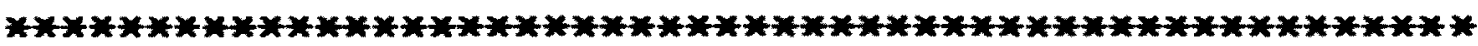

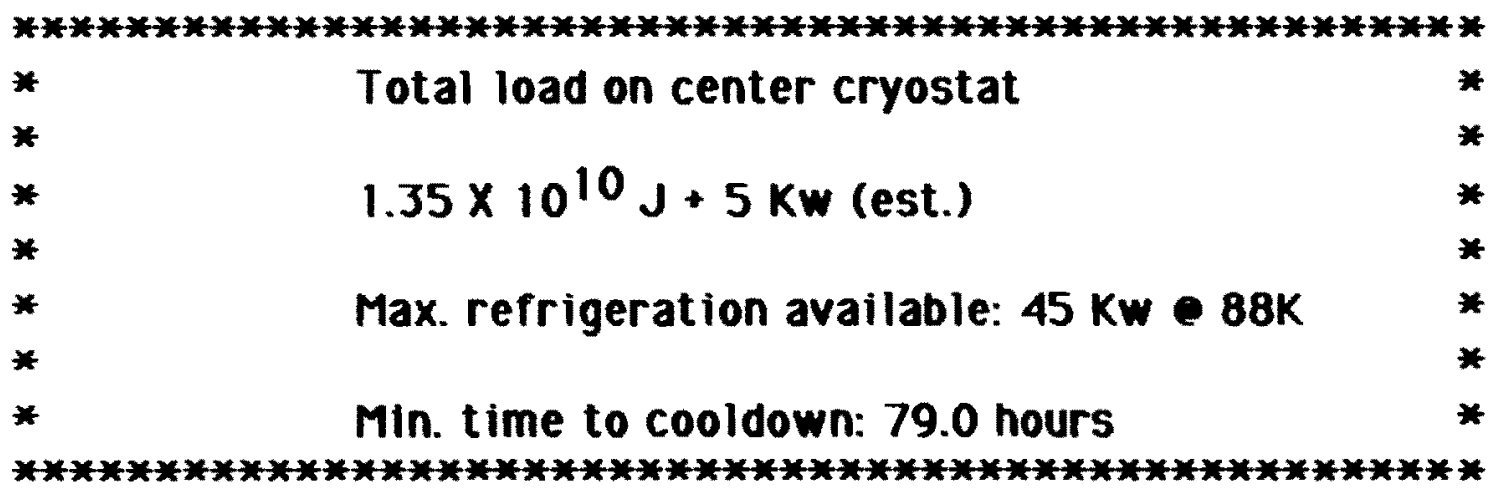

